\title{
Scientific globalism during a global crisis: research collaboration and open access publications on COVID-19
}

\author{
Jenny J. Lee ${ }^{1}$ iD $\cdot$ John P. Haupt ${ }^{1}$ \\ Published online: 24 July 2020 \\ (C) Springer Nature B.V. 2020
}

\begin{abstract}
This study sought to understand the nature of scientific globalism during a global crisis, particularly COVID-19. Findings show that scientific globalism occurs differently when comparing COVID-19 publications with non-COVID-19 publications during as well as before the pandemic. Despite the tense geopolitical climate, countries increased their proportion of international collaboration and open-access publications during the pandemic. However, not all countries engaged more globally. Countries that have been more impacted by the crisis and those with relatively lower GDPs tended to participate more in scientific globalism than their counterparts.
\end{abstract}

Keywords COVID-19 · Geopolitics · China $\cdot$ USA $\cdot$ International collaboration

The coronavirus disease of 2019, COVID-19, is undoubtedly the most pressing topic in global science research today. While scientists in every major region of the world are scrambling to understand and halt the virus' spread, national tensions are increasing. Accusations about what country is to blame, what country is hoarding medical supplies, and what country will develop the vaccine, and the extent it will be shared, have fueled international tensions. Governmental warnings about the stealing of COVID-19 research data (National Cyber Security Centre, 2020) and accusations about the intentional spread of misinformation by some countries (Moore, 2020) has made international cooperation more challenging than in the past. Previous research suggests that such geopolitical tensions can slow global recovery from COVID-19 (Scott, 2020). Given the unprecedented nature of this health crisis and the surrounding

Jenny J. Lee and John P. Haupt contributed equally to this work.

Jenny J. Lee

jennylee@arizona.edu

John P. Haupt

hauptj@email.arizona.edu

1 Center for the Study of Higher Education, University of Arizona, 1430 East Second Street, Tucson, AZ 85721, USA 
geopolitical environment, this study sought to understand the nature of scientific globalism, specifically via international collaboration and open-access publications, during a global crisis.

\section{Scientific publication and international collaboration patterns}

With one out of five research articles having authors from more than one country (NSF, 2019), the value of international research collaboration is undisputed. Past studies have well established that internationally coauthored publications result in greater impact, as often measured by a higher number of citations, compared with domestic publications (Adams, 2013; Chinchilla-Rodríguez, Vargas-Quesadab, Hassan-Monterob, González-Molinab, and Moya-Anegóna, 2010; Leta and Chaimovich, 2002; Smith, Weinberger, Bruna, \& Allesina, 2014). This greater influence is attributable to more scholarly expertise, resources, and standards (Georghiou, 1998) as well as the "social dynamics of science," which lead to wider specialized networks and a larger audience (Sun, Kaur, Milojevic, Flammini, \& Menczer, 2013, p.1). International research collaboration is especially prevalent in applied research fields (Luukkonen, Persson, and Siversten, 1992), while basic and applied fields are also collaborating (Coccia \& Wang, 2016). From a nation-state perspective, international research collaborations offset domestic skill shortages, even in the most advanced economies, including the USA and UK (Adams, 2013). From a global perspective, science is advanced in addressing broad concerns and crises, including pandemics. In reference to COVID-19, Mukhisa Kituyi the Secretary-General of the United Nations Conference on Trade and Development referred to international collaboration as the "engine of global science" and stated, "It is thus crucial that scientific responses are based on international collaboration that brings together the best minds and available data from different countries for the benefit of all" (Kituyi, 2020, para. 16).

When it comes to the world's leading scientific knowledge producers, the two global superpowers, the USA and China, are at the top. The two countries each account for about $25 \%$ of the world's total research and development (R\&D) expenditures, while the remaining top countries account for over a third of the global total: Japan, Germany, South Korea, France, India, the United Kingdom, Russia, Brazil, Taiwan, Italy, Canada, Spain, Turkey, and Australia (National Science Foundation, 2019). Between the top two research-producing countries, China overtook the USA in 2017 in science and engineering publications, having experienced a fivefold increase within just 15 years (NSF, 2018), which is about twice as fast as the world's average for the past decade (NSF, 2019). The USA and the European Union lead in global impact, as measured by the top $1 \%$ of articles cited, while China's citation measure is increasing (NSF, 2018). This comparative trend is consistent with overall patterns by levels of national development. In comparing the world's share of science and engineering articles over the past decade, high-income countries generally produce the most, but the growth rate has been minimal (1\% per year), while upper-middle income countries' rate of publications has been steadily rising (9\% per year) (NSF, 2019).

Over time, global networks have expanded and have become increasingly interconnected (Wagner \& Leydesdorff, 2005). When measuring the volume of internationally co-authored articles, the USA and China collaborate more with each other than any other country (Nature Index, 2019). While the two countries remain at the forefront of scientific knowledge production, other high-producing countries have higher rates of international collaboration: the UK (62\%), Australia (60\%), France (59\%), Canada (56\%), Germany (53\%), Spain (53\%), and Italy (50\%), compared with the USA (39\%) and China (21\%) (NSF, 2019). Regional cooperation also 
matters, as demonstrated by the EU, for reasons having to do with size, geographic proximity, and political support (Wagner, 2018; Wagner \& Leydesdorff, 2005). The drivers and benefits for countries can vary. For low-income countries, international research can develop their scientific capacity and output, while higher-income countries gain field access to special data and global exposure (Engels \& Ruschenburg, 2008; Leather, Butterfield, Peachey, Silverman, \& Sheriff, 2010; Iglic, Doreian, Kronegger, \& Ferligoj, 2017).

\section{International research collaboration during global crisis}

Recent research has examined mixed patterns of international collaboration during global emergencies. Similar to past trends, China and the USA lead in COVID-19 scientific output (Hook \& Porter, 2020; Hossain, 2020; Chahrour, Assi, Bejjani, et al., 2020). Based on a social network analysis of the current and past coronaviruses research over the past two decades, Tao et al. (2020) found that while the USA has the highest level of degree centrality or has the highest impact on other countries (followed by France and the UK), research teams are relatively scattered, as demonstrated by the study's low-density global map. Bibliometric studies further identified a positive relationship between COVID-19 cases and publications; countries that were most affected by COVID-19 also produced the most scientific documents (Dehghanbanadaki, et al., 2020; Zhang, Zhao, Sun, et al., 2020), but this pattern was not always consistent. It was also observed that some of the countries especially hit by the current coronavirus (i.e., Italy and Iran) produced disproportionately fewer articles, suggesting a research shortage based on an overstrain of healthcare facilities and physicians, which took precedence over publishing observational studies and case reports (Chahrour, Assi, Bejjani, et al., 2020).

Although there are fewer publications on international collaboration patterns during COVID-19, there are some additional insights from the earlier coronavirus pandemic, known as severe acute respiratory syndrome (SARS or SARS-COV) in 2003, affecting 29 countries and resulting in 774 known deaths. According to a bibliometric study of SARS publications, international collaboration rates tended to be low, with English-speaking countries, particularly the USA and the UK dominating the production (Chiu, Huang, \& Ho, 2004). The same study found that out of 32 countries with SARS cases, less than half did not produce a single SCI publication. A broader bibliometric study based on publications of WHO's eight emerging pathogens, which included SARS, found that international collaboration ranged from 12.1 to 86.9\% (Sweileh, 2017). The same study also found that among these topics, SARS ranked first in quantity, followed by Ebola and Crimean-Congo, suggesting a higher number of studies associated with higher case incidents. The countries most affected, however, do not produce the most articles; the countries with the highest number of publications in different areas were China (SARS), the USA (Ebola), and Turkey (Crimean-Congo). The peaks in publication rates corresponded with the timeframe of the respective outbreaks, as was also found for COVID-19 publications (Zhang, L., Zhao, W., Sun, B. et al., 2020).

Fewer studies have examined international research dynamics during a global crisis. Based on a case study of SARS research, Lee (2008) observed the unavailability of modern technology, such as the availability of genome sequencing machines for some groups. It may be for this reason that less-resourced countries are more likely to be involved in international research collaboration than independent research (Pouris \& Ho, 2016; Iglic, Doreian, Kronegger, \& Ferligoj, 2017). Lee (2008) also identified covert competition for publication and patents between scientists and worries that genomic information would be withheld until intellectual property 
rights were secured. Besides reasons having to do with rivalry, new knowledge might be suppressed due to political or cultural factors. From the perspective of a Chinese research team, reasons having to do with "a lack of coordination and collaboration, stifling political influence, hesitation to challenge authorities, and isolation from the rest of the world" contributed towards a missed opportunity in sharing their major SARS findings (Enserink, 2003, para 7). As demonstrated in the latter case, political factors can play a crucial role.

\section{COVID-19 and geopolitical tensions}

While the world is facing an unprecedented global health crisis affecting almost every country, geopolitical tensions are rising, particularly around the source of the coronavirus and information sharing. As US leaders have referred to COVID-19 as the "Chinese Virus" or "Wuhan Virus," Chinese leaders have suggested that the SARS-CoV2 virus was brought to Wuhan by the US Army (Crowley, Wong, \& Jakes, 2020). Australia's call, with support from the USA, UK, and France, for a probe on COVID-19's origins, has also added to diplomatic tensions with China (Mercer, 2020). As scientists throughout the world are racing to halt the current pandemic's spread, US and UK authorities issued a joint statement warning against malicious cyber activity, including intelligence on national healthcare policy and sensitive data on COVID-19-related research (National Cyber Security Centre, 2020). More explicitly, the US Director of the National Counterintelligence and Security Center indicated that information on a possible vaccine would be a "huge prize," but "we have full expectation that China will do everything in their power to obtain any viable research that we are conducting here in the U.S." (Myre, 2020, para. 7). US policymakers have also suggested that any coordination with China is "a self-harming exercise in a zero-sum competition for global leadership" (Hass \& Doug, 2020, para 3). The US president also threatened to permanently cut funding to the World Health Organization (WHO) because of its alleged pro-China bias (Restuccia, Lubold, \& Hinshaw, 2020). The effect of such a cut would be substantial given the USA is the world's largest sponsor to the WHO, contributing $15 \%$ of the organization's $\$ 4.8$ billion budget (Togoh, 2020). Meanwhile, the Chinese government announced that funded studies on coronaviruses are to be published in local, over international, Chinese journals (Larivière, Shu \& Sugimoto, 2020). This move aligned with a broader research-evaluation reform initiative that prioritizes domestic needs and ultimately publishes in domestic over SCI journals (Huang, 2020; Tao, 2020). While most media attention related to such geopolitical tensions has involved China, strains are also occurring elsewhere. On April 2020, two prominent French doctors suggested that Africa should serve as the laboratory for vaccine testing, sparking a widespread public outcry and reminders of the continent's colonial past with Europe (Kossoff, 2020). The following month, the USA shunned a global virtual meeting organized by Europe in raising $\$ 8$ billion for vaccine research, noting that the USA is already investing billions of dollars in its own domestic efforts (Stevis-Gridneff \& Jakes, 2020).

\section{Scientific globalism}

The conceptual framework for this study is scientific globalism, sometimes referred to as technoglobalism (Cantwell \& Grimm, 2018). According to Sá and Sabzalieva (2018), scientific globalism's basic mission is for the advancement of knowledge and open science, which can be 
contrasted to scientific nationalism's focus on economic competitiveness and nation-building. Scientific nationalism, on the other hand, views scientific and technological advancement as a way to ensure national security, strengthen economic advantage, and signal national prestige (Sá \& Sabzalieva, 2018). They found that both logics coexist, despite various tensions and contradictions in policy. Cantwell and Grimm (2018) similarly propose that academic science is both a global and cooperative enterprise as well as a nationalist endeavor in competition with state rivals. In the case of China, Cantwell and Grimm suggest that the country's rise is a consequence of savvy technonationalism, whereas the USA and UK's nationalism policies, in favor of right-wing populism, have limited their scientific enterprise. Marginson (2018) further explains that China's successful "national/global synergy" over the past 40 years can be explained as follows, "China's rise in science and higher education lies on one hand in the global conditions (the evolving global science system), on the other hand in the national conditions, and especially the conjunction between global and national drivers that national policy achieved" (p. 492). In a study of co-publications between the AUS and China over the past 5 years, Lee and Haupt (2019) also found that scientific research can be both national and global pursuits as a positive sum endeavor. From a scientific nationalism view, the authors found that despite USA attempts to curb international research engagement with China, the USA benefits from China's contribution to US research productivity. From a scientific globalism lens, global science is advanced as demonstrated by the two country's increasing co-authored scientific papers, at least prior to COVID-19.

In essence, scientific globalism (as well as scientific nationalism) will endure as long as there is international collaboration in research, but the concepts are not interchangeable. Global research participation is uneven and will always be at least somewhat shaped by national, multinational, and commercial interests. Based on their social network analysis of global science, Wagner and Leydesdorff (2005) found that the global research network is self-organizing, without any central authority directing science and that national interests alone do not explain the extent of international linkages being created. That is, international collaboration networks are "growing independently of and orthogonally to national systems of science. The national systems continue to operate, but they are affected by the emerging global system" (p. 205).

This emerging global system is largely shaped by highly resourced nations. As Peters (2006) observes, global science has long been subject to Western control and bias, making international collaborations an imperfect proxy to global science. Center-periphery country relationships are thus not always equal or mutually beneficial. International collaborations may reflect competitive national agendas or private interests and thus are not always intended towards the global public good. Likewise, domestically produced research has also benefitted global society. The scientific global system, thus, has to be understood in relation to the importance that international ties play in enabling resources to be pooled and maximally exploited in ways that national research might be limited. Smaller national scientific systems tend not to allow for high levels of specialization, making international collaboration especially vital (Iglic, Doreian, Kronegger, \& Ferligoj, 2017; Engels \& Ruschenburg, 2008; Luukkonen et al. 1992). Collaboration benefits not only low-income but also high-income countries as well but for different reasons, often having more to do with accessing specimens and data, extending global networks and audiences and research labor (Leather, Butterfield, Peachey, Silverman, \& Sheriff, 2010; Cantwell \& Lee, 2010). Thus, beyond the focus on public global goods, scientific globalism reflects cross-border networks towards the goal of extending science, regardless of the social impact. International collaboration becomes a key means of achieving this goal.

As an extension of scientific globalism, this study also considered open access. While knowledge production, in the form of research publications, is synonymous to scientific 
progress, accessibility to knowledge tends to be either assumed or disregarded. Lower-income countries in particular are on the scientific "periphery" as they have long been disadvantaged by the unaffordability of journal subscriptions, which Chan, Kirsop, and Arunachalam (2005) refer to as "information famine" (para. 12). Their ability to fully participate and contribute to global science becomes hindered (Salager-Meyer, 2008; Chan, Kirsop, and Arunachalam, 2005) as past research has well established that a country's economic status is highly linked to its research productivity (King; 2004; Jaffe, ter Horst, Gunn, Zambrano, \& Molina, 2020). From a global view, open-access allows for unrestricted access to scientific knowledge in the form of free online publications. Open-access is not, however, without its limitations, including authorpay models, sometimes with no quality control, giving rise to predatory publishers (Haug, 2013). Despite such challenges, open access allows researchers in less represented parts of the world to participate in the international research community while also allowing researchers in higher-income countries to also access local research and knowledge towards the resolution of the world's major problems (Chan et al., 2005). In fact, Kieńć (2017) found that researchers from peripheral countries preferred open-access journals for promotional as well as citation advantages. The average researcher from these countries published $46 \%$ of their works in gold open-access journals, referring to an academic publication made freely available on a publisher's website without embargo, compared with $20 \%$ for the average researcher from the socalled core countries. During the current pandemic, numerous efforts to make COVID-19 research accessible went into effect. In the beginning of 2020, publishers, funders, and scientific societies signed a statement committing to data sharing and making findings immediately available to address the health crisis (Wellcome, 2020a). Over 30 major academic publishers, including Elsevier, Wiley, Springer, Taylor and Francis, and others unlocked tens of thousands articles (Change, 2020; Wellcome, 2020a). Artificial-intelligence tools to extract specific findings and bridge fields to navigate the fast-rising number of research papers were being developed as well (Hutson, 2020). Publications in machine-readable formats and open licenses were especially key for this purpose (Wellcome 2020b).

\section{Methods}

This study sought to understand patterns of scientific globalism during a global crisis. While previous research suggests international collaboration is heightened, the current pandemic is occurring in the midst of an unusually tense geopolitical climate. There is also little known about how the extent of scientific globalism compares with the pre-crisis. Thus, this study specifically focused on internationally authored scientific articles on COVID-19 published at the beginning of January 2020 to early May 2020 to observe the extent of international collaboration and open access compared with (a) the past five pre-pandemic years and (b) non-COVID-19 articles published during the same 2020 time period. Past research has also observed some discrepancies by countries, while this study also sought to more systematically understand the relative effects of past patterns, COVID-19 cases, and country wealth on scientific globalism across all countries that produced COVID-19 research.

\section{Bibliometric data and filtering}

The study was based on bibliometrics, utilizing statistical methods to analyze publications. This approach is commonly used to systematically examine research collaborations given the 
limitations of surveys and observations (Subramayan, 1982). The data for this scientometric study was collected using Scopus (Elsevier, 2020), the world's largest comprehensive abstract and citation indexing database of primary documents from serial publications (journal articles, conference papers, reviews, editorials, books, book chapters, letters, errata, notes, short surveys, and business articles), which also includes open-access publications. Scopus and Web of Science (WoS) are the most commonly used databases in bibliometric studies. While neither can perfectly account for all research studies and both tend to over-represent English language journals as well as under-represent Social Sciences, Arts, and Humanities fields, Scopus offers a higher number of journals, including publications outside the USA and greater field coverage than WoS (Mongeon \& Paul-Hus, 2016; Tabacaru, 2019). A strict criterion of "articles," which Scopus defines as "original research or opinion," most commonly found in peer-reviewed journals (Elsevier, 2017, p. 10) served as the primary data for this study.

Three datasets were created and compared: (a) all article publications from January 1, 2015, to December 31, 2019 (2015-2019), (b) non-COVID-19 articles from January 1, 2020, to May 9, 2020 (non-COVID-19 2020), and (c) COVID-19 article publications from January 1, 2020, to May 9, 2020 (COVID-19 2020). To produce these data sets, country ${ }^{1}$-specific publication information was downloaded from Scopus that included a country's total number of publications and a country's total number of domestic-only publications. The latter measure was obtained for each country by excluding all other countries in the Scopus advanced search window. A country's total number of international collaborations was calculated by subtracting its total number of publications by its total number of domestic-only publications. Finally, articles were assigned to countries on a full count basis, so that an article was counted towards each co-authoring country's total number of publications. The latter two datasets were based on the inclusion (COVID-192020) or exclusion (non-COVID-192020) of articles containing at least one of the following phrases, "COVID-19," "2019-ncov, "SARS-CoV2 ," and "novel coronavirus," in the title, abstract, and keywords fields during this time frame. January 1, 2020, was selected as the starting point that soon led up to COVID-19 being declared as a pandemic by the World Health Organization (WHO). Based on the WHO (2020a) timeline, on December 31, 2019, a novel coronavirus was identified, as the Wuhan Municipal Health Commission in China reported a cluster of pneumonia cases in Wuhan, Hubei Province. Since that date, COVID-19 quickly accelerated and was declared a pandemic on March 11, 2020. At the time of writing this study, June 2020, scientists are still learning about the SARS-CoV2 virus and how to best contain it. Given the particular interest in global science research during a global crisis, most of the analyses were based on the COVID-19 bibliometric data, which was based on 111 countries that produced at least one COVID-19 article during January 1, 2020, to May 9, 2020.

Next, two of the three datasets, 2015-2019 articles and COVID-192020 articles, were merged together, along with information on each of the 111 countries' economy size and COVID-19 cases. Gross domestic product (GDP), the most commonly used variable to measure the extent of economic activity with a country, was derived from the most recent available data from the World Bank (2020). As it pertains to this study, a country's GDP represents a country's capacity to conduct scientific research. While Research and Development (R\&D) expenditures would have provided a clearer measurement of scientific capacity, 16 of the 111 countries were missing this data in both the World Bank and UNESCO databases. To have conducted the analyses with the

\footnotetext{
${ }^{1}$ Hong Kong and Macao were classified separately from China in Scopus. For the ease of reading, all countries/ regions/territories are referred to as "countries."
} 
limited R\&D data would have eliminated these lower-income countries in the regression findings. The number of COVID-19 cases per country as of May 2020 was obtained from the World Health Organization (WHO) reports (2020b) and scaled by population.

\section{Scientific globalism measures}

To examine scientific globalism, two areas were observed: international collaboration and open-access. International collaboration was measured by international co-authorship, a commonly accepted scientific indicator to study research collaboration patterns (Laudel, 2002; Lundberg, Tomson, Lundkvist, Skår, \& Brommels, 2006). For this study, international collaborations were identified as co-authored article publications that included authors from more than one country (Lee \& Haupt, 2019). Open access was measured as a filter option within Scopus, to identify that the article publication does not have a paywall or any other access restriction, regardless of the level of journal access (Scopus, 2018). Scopus identifies open access on an article by article basis as opposed to journal by journal or publisher by publisher.

\section{Data analyses}

For the 2015-2019, non-COVID 2020, and COVID-192020 data, the percentage of international collaborations and the percentage of open access articles were calculated and compared. Chi-square tests of independence were performed to compare the percentage of international collaborations as well as the percentage of open access for the following: (a) 2015-2019 articles with the COVID-192020 articles and (b) for the non-COVID-192020 articles with the COVID-192020 articles. The same tests and comparisons were also applied to each of the top 25 COVID-19 research-producing countries. Although comparisons were not made between each of the 25 countries, the results provided insight into increases or decreases in rates of collaboration for each of the top-producing countries.

While these rates of collaboration by country demonstrate how global patterns are not uniform, they do not indicate country-level characteristics to explain such differences. Thus, we used a generalized linear model (GLiM) to systematically understand the factors that contribute to the extent of a country's proportion of (a) international collaboration on COVID-19 and (b) open access on COVID-19. The events variable was (a) the number of internationally authored COVID192020 articles or (b) the number of open-access COVID-192020 articles. The trials' variable was the total number of COVID-192020 articles. The predictors included 2015-2019 international collaboration/open access, the number of COVID-19 cases, and GDP. The 2015-2019 variables served as control measures to examine the unique effects of the global crisis. The number of COVID-19 cases was used to examine the extent to which each country's COVID-19 situation influenced the extent of global participation. Finally, GDP was included to examine the extent to which country wealth played a role given that past research has demonstrated a positive relationship between GDP and scientific publication output statistics (Samimi \& Roshan, 2011).

\section{Findings}

In total, 3401 articles were published on COVID-19 from January 12, 2020, to May 9, 2020. As shown in Fig. 1, 111 countries published at least 1 article on the topic and represented all major geographic regions of the world. The top five producers were China (1079), the USA (624), Italy (310), the UK (209), and India (141). 


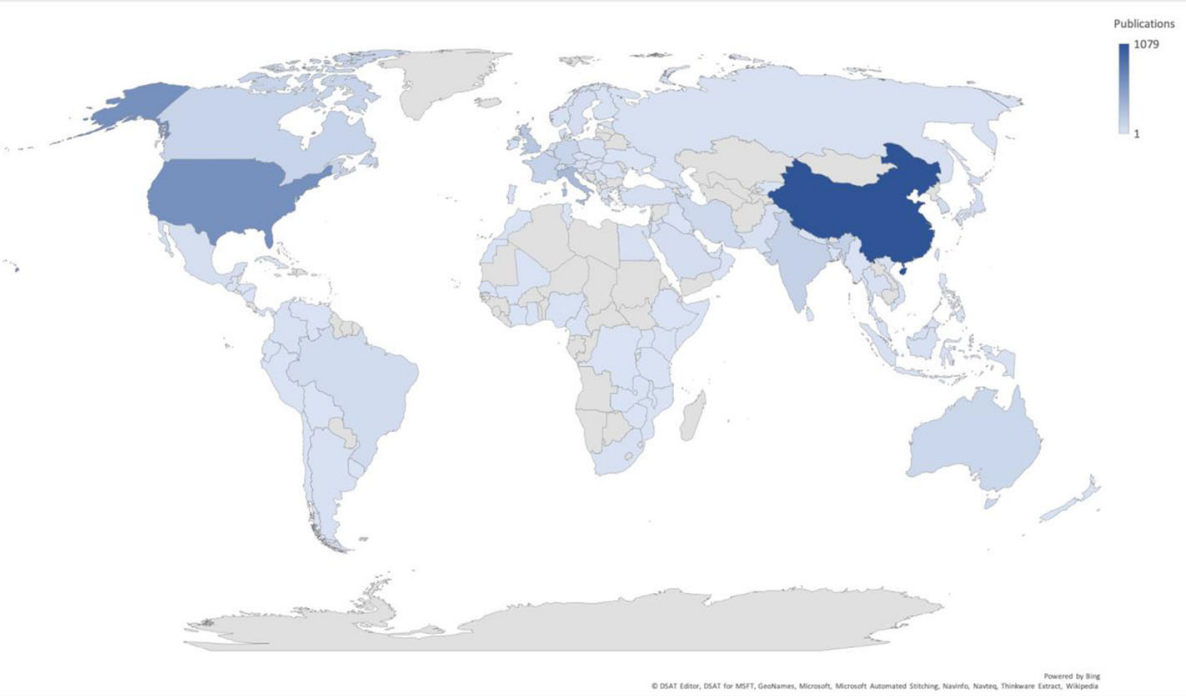

Fig. 1 Map of the 111 countries that published articles on COVID-19 from January 12, 2020, to May 9, 2020

Note: The color shade of the countries ranks them by the number of articles published

\section{Comparing COVID-19 and pre-COVID-19 time periods}

\section{International collaboration}

The extent of international collaboration on COVID-19 is higher than recent years, prior to the global crisis, and higher than non-COVID-19 2020 research. Table 1 displays the extent of international collaboration during (a) 2015-2019, (b) non-COVID-192020, and (c) COVID192020. Among the 3401 COVID-192020 publications, about a third were based on international collaborations. As shown in the last column, the percentage of international collaboration on COVID-192020 publications is higher compared with the past 5 years $(33.58 \%$; $23.41 \%$, respectively). According to the chi-square test, there is a significant difference on the percentage of international collaborations when comparing these two data points $\left(\chi^{2}(1)=\right.$ $196.018, p<.001)$. Furthermore, the percentage of international collaborations on COVID-19 publications was also significantly higher than non-COVID-19 publications in the same time frame $\left(\chi^{2}(1)=54.794, p<.001\right)$. In sum, international collaborations accounted for $5.7 \%$ more of the COVID-192020 publications than the non-COVID-192020 publications and $10 \%$ more than all international publications prior to the pandemic.

While international collaboration on COVID-19 has generally increased as measured by the percentage of international collaborations compared with the recent pre-pandemic period, there are varying patterns by countries. Among the top 25 top countries producing articles on COVID19, the extent of international collaboration before 2020 and on COVID-19 since 2020 varies (see Appendix Table 5). Among the countries with significant differences between these periods, most countries (8 out of 13) demonstrate a higher proportion of international collaboration on COVID19 compared with past international collaboration. On the other hand, China, the lead producer of COVID-19 research, had a significantly lower percentage (20\%) of international collaborations 
Table 1 Frequencies of single country publications and international publications for articles published between 2015 and 2019, for non-COVID-192020 articles and for COVID-192020 articles

\begin{tabular}{llllll}
\hline Time period & $\begin{array}{l}\text { Total } \\
\text { publications }\end{array}$ & $\begin{array}{l}\text { Total single } \\
\text { country - } \\
\text { publications }\end{array}$ & $\begin{array}{l}\text { \% Single } \\
\text { country } \\
\text { publications }\end{array}$ & $\begin{array}{l}\text { Total } \\
\text { international } \\
\text { collaborations }\end{array}$ & $\begin{array}{l}\text { \% International } \\
\text { collaborations }\end{array}$ \\
\hline $2015-2019$ & $10,043,064$ & $7,691,933$ & $76.59 \%$ & $2,351,131$ & $23.41 \%$ \\
Non-COVID-192020 & 679,600 & 490,187 & $72.13 \%$ & 189,413 & $27.87 \%$ \\
COVID-192020 & 3401 & 2259 & $66.42 \%$ & 1142 & $33.58 \%$ \\
\hline
\end{tabular}

on COVID-19 research than on research over the past 5 years $(22.48 \%)$. The USA, the second lead producer, shows slightly upward activity (from 39.94 to $42.95 \%$ ), but this difference is not significant. Among the biggest significant differences from the proportion of international collaborations prior to and on COVID-19 are Singapore (-28.1\%), Austria (20.41\%), Belgium (19.26\%), Japan (19.13\%), and Canada (18.95\%).

In comparing the percent of international collaborations for COVID-19 and non-COVID192020 publications, similar to the comparison with the 2015-2019 data, the majority of countries (6 out of 9 ) that had significantly different rates of collaboration had a higher percent of international collaborations on COVID-192020 publications compared with non-COVID192020 publications. Additionally, China's percentage of international collaborations on COVID-192020 publications was significantly lower $(-4.98 \% ; p<.001)$ than their nonCOVID-192020 publications, and there remained no significant difference for the USA between the two time periods. Lastly, the countries with the largest significant differences changed slightly. Singapore had the highest change of $-32.79 \%$ followed by France $(-21.34 \%)$, Austria (16.38\%), Canada (14.89\%), and the Netherlands (14.06\%).

\section{Open access}

Results further indicate that among these 111 countries combined 3401 COVID-19 articles, three-fourths are open access (see Table 2). This percentage is significantly higher than the percentages for the 2015-2019 articles and the non-COVID-192020 articles. For 2015-2019 article publications, only $28.90 \%$ of publications were labeled as open access compared with $75.74 \%$ of publications on COVID-19 $\left(\chi^{2}(1)=3628.209, p<.001\right)$. Likewise, only $32.04 \%$ of non-COVID-192020 publications were labeled as open access, which is $43.7 \%$ less publications than for COVID-192020 publications $\left(\chi^{2}(1)=2956.503, p<.001\right)$.

For each of the top 25 COVID-19 research-producing countries, there was a noticeably higher proportion of open-access articles on COVID-19 than during the past 5 years and on non-COVID-192020 publications during the same period, with all differences being significant except for one (see Appendix Table 6). Whereas the percentage of open-access articles on research during 2015-2019 ranged from 18.08 to 46.19\% and on non-COVID-192020 research from 22.59 to $58.95 \%$, the percentage of open-access articles on COVID-19 research ranged from 61.70 to $93.48 \%$. Among the biggest jumps in comparing the 2015-2019 publications with COVID-192020 publications were in East Asia; the top difference was Hong Kong (65.06\%), followed by Singapore (60.31\%), South Korea (60.13\%), and Taiwan (59.68\%), all noticeably higher than China (45.16\%). While the largest increases when comparing non-COVID-192020 publications with COVID-192020 publications were in East Asia and North America, Hong Kong (61.75\%) and Singapore (58.48\%) remained at the top of 
Table 2 Frequencies of open access and non-open-access publications for articles published between 2015 and 2019, for non-COVID-192020 articles and for COVID-192020 articles

\begin{tabular}{llll}
\hline Time period & Non-open access & Open access & \% Open access \\
\hline 2015-2019 & $7,140,116$ & $2,902,948$ & $28.90 \%$ \\
Non-COVID-192020 & 461,811 & 217,789 & $32.04 \%$ \\
COVID-192020 & 825 & 2576 & $75.74 \%$ \\
\hline
\end{tabular}

countries with the largest difference followed by Canada $(57.85 \%)$, the United States (55.49\%), and South Korea (53.91\%).

\section{Country-level influences on scientific globalism}

The GLiM results indicate the relative country-level contributions of past patterns, COVID-19 cases, and GDP on COVID-19 international collaborations and COVID-19 open-access articles. As shown in Table 3, each of the independent variables significantly predicts COVID-19 international collaboration. Past international collaborations and the number of COVID-19 cases increase the likelihood of international collaboration on a COVID-19 publication $[\operatorname{Exp}(B)=1.04 ; 1.06$, respectively], whereas GDP has a negative impact $[\operatorname{Exp}(B)=.95]$. In essence, countries with a strong record of international collaboration have continued to collaborate on COVID-19, but this likelihood is also influenced by the extent of their cases and GDP. Whereas the number of cases increases the probability, their relative wealth would lead them to collaborate less, likely given their already large domestic output. In examination of the countries with the highest international research collaboration on COVID-19 (Austria, Belgium, Netherlands, Hong Kong, and Saudi Arabia), their GDP is a much smaller fraction compared with the larger economies of the USA, China, Japan, Germany, and the UK.

When examining the effects of producing COVID-19 articles as open access, the number of COVID-19 cases again had a positive effect $[\operatorname{Exp}(B)=1.09]$ and GDP had a slightly negative effect $[\operatorname{Exp}(B)=.97]$ (see Table 4). Pre-COVID-19 open-access articles did not have a significant influence. Based on the 111 countries that produced COVID-19 articles, the extent to which these countries were hit by COVID-19 mattered, but the relatively higher wealth of top GDP countries suggest a greater likelihood of publishing COVID-19 research as restricted articles.

Table 3 Final generalized linear model on the influences of past international collaboration, COVID-19 cases, and GDP on COVID-19 international collaboration ( $N=111$ countries)

\begin{tabular}{llllll}
\hline Parameter & $\mathrm{B}$ & Std Error & Exp(B) & 95\% CI for Exp(B) & $p$ value \\
\hline \% Int Authors 2015-19 & .03 & .00 & 1.04 & $1.03-1.04$ & $<.001$ \\
COVID-19 cases* & .05 & .02 & 1.06 & $1.02-1.09$ & .001 \\
GDP** & -.05 & .02 & .95 & $.93-.98$ & .002 \\
\hline
\end{tabular}

Goodness of fit: Deviance value/df $=2.41$

*In 100 -thousands

**In trillions 
Table 4 Final generalized linear model on the influences of past open-access articles, COVID-19 cases, and GDP on COVID-19 open-access articles $\left(N=110^{*}\right.$ countries $)$

\begin{tabular}{llllll}
\hline Parameter & B & Std Error & $\operatorname{Exp}(\mathrm{B})$ & $95 \%$ CI for Exp(B) & $p$ value \\
\hline \% Open access 2015-2019 & .02 & .01 & 1.02 & $.99-1.05$ & .277 \\
COVID-19 cases** & .08 & .02 & 1.09 & $1.05-1.12$ & $<.001$ \\
GDP*** & -.03 & .01 & .97 & $.94-1.00$ & .023 \\
\hline
\end{tabular}

Goodness of fit: Deviance value/df $=1.96$

*1 case (Slovakia) was dropped as the number for COVID-19 (2) was higher than for 2015-2019 (1)

***In 100-thousands

*** In trillions

\section{Discussion}

This study sought to explore the nature of scientific globalism, as measured by the extent of scientific research collaboration and open-access articles on COVID-19 and how they compare to non-COVID-19 research (a) during the pandemic as well as (b) the past five pre-pandemic years. The study also examined the degree to which the number of COVID-19 cases and economic wealth influences these patterns. Although geopolitical tensions are ongoing, the extent of scientific globalism is generally higher in times of a global crisis and on the global crisis issue. The findings support past research that research productivity increases during public health emergencies (Zhang, Zhao, Sun, et al., 2020) and that most COVID-19 research is produced within countries, with China leading in COVID-19 publications (Hook \& Porter, 2020; Hossain, 2020; Chahrour, Assi, Bejjani, et al., 2020). Further analyses showed variations by countries and that while a country's prior patterns mattered in collaborating on internationally authored publications, the extent to which the country was affected by COVID-19 increases the likelihood they would participate in international collaboration. However, in observing open-access patterns, the country's past pattern of publishing in open access prior to the pandemic had no significant bearing on publishing in open access during this particular global crisis. Similar to international collaborations, what did make a clear difference in open access was the extent to which a county was affected by COVID-19.

The same analyses also showed that the higher the GDP, the lower the odds of international collaboration and open-access publishing during a global crisis. In other words countries with a higher GDP, already producing a high domestic output, which also tend to be in restricted journals, may not engage in as much scientific globalism (via international collaboration and open-access publishing) compared with their lower GDP counterparts. Countries with a high GDP have resource concentrations (i.e., funds, equipment, staffing), which are necessary to solve problems and which makes them less dependent on outside collaborators. As demonstrated by China and the USA, there is an especially high volume and global proportion of domestic output. The two countries also have high COVID-19 caseloads, indicating a lesser need to obtain data or conduct field research abroad, which also help to explain their relatively little change in international collaboration patterns. For countries with a lower GDP and predictably smaller-sized science systems, there is a greater dependency on international collaboration, particularly to mobilize resources (Iglic, Doreian, Kronegger, \& Ferligoj, 2017) and on open-access outlets (Kieńć; 2017). Previous research identified a positive 
relationship between resource concentration and researchers' collaboration propensity; scarce resources push researchers to work together (Birnholtz, 2007). Another study found that a coauthor having special data or equipment motivated $20 \%$ of article collaborations (Melin, 2000). In the case of COVID-19, limited available specimens during the early part of 2020 and the costs to generate and analyze the data, combined with urgency of addressing the global health crisis helps to explain the significantly increased rate of international COVID-19 research output worldwide and why the countries with higher cases were generally more inclined or sought after to collaborate. As a past study found that researchers in small countries and working in very specialized fields are more likely to collaborate internationally (Iglic, Doreian, Kronegger, \& Ferligoj, 2017), the unprecedented nature and novelty of COVID-19 may further explain the overall international collaboration increase among lower GDP countries and those with higher COVID-19 cases.

In addition to these findings, the study more broadly extends how scientific globalism is understood and opens up several future lines of research. As this study argued upfront, scientific globalism reflects cross-border networks towards the goal of extending science, regardless of the impact. International collaboration becomes a key means of achieving this goal. Additionally, scientific globalism should also require knowledge dissemination as a requisite to further scientific advancement given that scholarly publications are not universally accessible. Beyond the COVID-19 cases and country GDP results, the globally coordinated effort to make COVID-19 research freely and widely available likely best explains the dramatic increase in open-access publications. While there are certainly other variables that might further operationalize scientific globalism, the data for this study was limited by the small dataset given the four-month COVID-19 time period. As the new coronavirus continues to spread and research on it continues, further research based on a larger dataset could consider a broader array of country-level factors, including country-level networks, the availability of open-source data, as well as the influence of multinational organizations to promote global agendas. The next step for the current study will be a more focused examination among the leading international collaborators, the USA and China, as geopolitical tensions are increasing.

Despite the limitations in capturing all possible dimensions of scientific globalism, this study already demonstrates that there are varying levels of country participation during a global crisis, at least mediated by the country's wealth and the impact of the global crisis. Obviously domestically produced research that has restricted access can still be a global good. The extent of global participation, however, is limited when research is conducted within a single country. Thus as our framework suggests, scientific pursuits are not either/or as both scientific globalism and scientific nationalism can coexist. What remains unknown is whether or how much more international collaboration, in particular, would have taken place if there was less geopolitical rivalry. An important question for future research is whether one impedes the other, particularly during a global crisis, as finding scientific solutions remains urgent.

Acknowledgements The authors would like to acknowledge Mark Bergstrom, University Information Technology Support at the University of Arizona for his assistance with the statistical analyses and the anonymous reviewers for their helpful comments. 


\section{Appendix}

Table 5 Frequencies of single country publications and international publications for articles published between 2015 and 2019, for non-COVID-192020 articles, and for COVID-192020 articles by top 25 country/region

\begin{tabular}{llllll}
\hline Country/region & Total & \% International & $\%$ International & $p$ value & \% International \\
& COVID-19 & collaborations on & collaborations \\
publications & COVID-19 & $2015-2019$ & $\begin{array}{l}\text { collaborations } \\
\text { non- }\end{array}$ \\
& & & & COVID-192020 \\
\hline
\end{tabular}

\begin{tabular}{|c|c|c|c|c|c|c|}
\hline China & 1079 & $20.02 \%$ & $22.48 \%$ & .05 & $25.00 \%$ & 0.00 \\
\hline United States & 624 & $42.95 \%$ & $39.94 \%$ & .12 & $42.68 \%$ & 0.89 \\
\hline Italy & 310 & $39.68 \%$ & $49.88 \%$ & .00 & $53.11 \%$ & 0.00 \\
\hline United Kingdom & 209 & $67.46 \%$ & $60.02 \%$ & .05 & $65.07 \%$ & 0.47 \\
\hline India & 141 & $26.95 \%$ & $18.60 \%$ & .01 & $21.97 \%$ & 0.15 \\
\hline France & 122 & $42.62 \%$ & $59.02 \%$ & .00 & $63.96 \%$ & 0.00 \\
\hline Canada & 118 & $74.58 \%$ & $55.63 \%$ & .00 & $59.69 \%$ & 0.00 \\
\hline Germany & 106 & $62.26 \%$ & $55.34 \%$ & .15 & $59.77 \%$ & 0.60 \\
\hline Australia & 93 & $69.89 \%$ & $57.55 \%$ & .02 & $62.92 \%$ & 0.17 \\
\hline Spain & 89 & $50.56 \%$ & $49.75 \%$ & .88 & $54.16 \%$ & 0.50 \\
\hline Iran & 74 & $31.08 \%$ & $21.91 \%$ & .06 & $31.82 \%$ & 0.89 \\
\hline Singapore & 74 & $40.54 \%$ & $68.64 \%$ & .00 & $73.33 \%$ & 0.00 \\
\hline Switzerland & 62 & $66.13 \%$ & $72.37 \%$ & .27 & $75.14 \%$ & 0.10 \\
\hline South Korea & 57 & $29.82 \%$ & $28.50 \%$ & .82 & $32.75 \%$ & 0.64 \\
\hline Netherlands & 54 & $81.48 \%$ & $63.91 \%$ & .01 & $67.42 \%$ & 0.03 \\
\hline Hong Kong & 53 & $75.47 \%$ & $74.60 \%$ & .89 & $77.73 \%$ & 0.70 \\
\hline Brazil & 52 & $46.15 \%$ & $32.14 \%$ & .03 & $40.12 \%$ & 0.38 \\
\hline Japan & 48 & $50.00 \%$ & $30.87 \%$ & .00 & $36.41 \%$ & 0.05 \\
\hline Taiwan & 46 & $39.13 \%$ & $35.20 \%$ & .56 & $42.80 \%$ & 0.62 \\
\hline Belgium & 44 & $88.64 \%$ & $69.38 \%$ & .01 & $74.62 \%$ & 0.03 \\
\hline Sweden & 37 & $70.27 \%$ & $65.53 \%$ & .54 & $69.07 \%$ & 0.87 \\
\hline Saudi Arabia & 36 & $75.00 \%$ & $77.41 \%$ & .73 & $78.61 \%$ & 0.60 \\
\hline Mexico & 33 & $42.42 \%$ & $42.86 \%$ & .96 & $50.03 \%$ & 0.38 \\
\hline Turkey & 33 & $27.27 \%$ & $22.86 \%$ & .55 & $30.31 \%$ & 0.71 \\
\hline Austria & 28 & $89.29 \%$ & $68.88 \%$ & .02 & $72.91 \%$ & 0.05 \\
\hline
\end{tabular}


Table 6 Frequencies of non-open access and open-access publications for articles published between 2015 and 2019, for non-COVID-192020 articles, and for COVID-192020 articles by top 25 country/region

\begin{tabular}{|c|c|c|c|c|c|c|}
\hline Country/region & $\begin{array}{l}\text { Open } \\
\text { access on } \\
\text { COVID-19 }\end{array}$ & $\begin{array}{l}\% \text { Open access } \\
\text { on COVID-19 }\end{array}$ & $\begin{array}{l}\text { \% Open access } \\
2015-2019\end{array}$ & $p$ value & $\begin{array}{l}\% \text { Open-access } \\
\text { non-COVID- } \\
192020\end{array}$ & $p$ value \\
\hline China & 732 & $67.84 \%$ & $22.68 \%$ & .00 & $26.23 \%$ & .00 \\
\hline United States & 541 & $86.70 \%$ & $32.20 \%$ & .00 & $31.21 \%$ & .00 \\
\hline Italy & 234 & $75.48 \%$ & $30.70 \%$ & .00 & $40.88 \%$ & .00 \\
\hline United Kingdom & 174 & $83.25 \%$ & $39.05 \%$ & .00 & $43.44 \%$ & .00 \\
\hline India & 87 & $61.70 \%$ & $22.12 \%$ & .00 & $19.02 \%$ & .00 \\
\hline France & 95 & $77.87 \%$ & $29.47 \%$ & .00 & $34.36 \%$ & .00 \\
\hline Canada & 106 & $89.83 \%$ & $30.94 \%$ & .00 & $31.98 \%$ & .00 \\
\hline Germany & 82 & $77.36 \%$ & $33.07 \%$ & .00 & $45.25 \%$ & .00 \\
\hline Australia & 78 & $83.87 \%$ & $28.96 \%$ & .00 & $31.76 \%$ & .00 \\
\hline Spain & 74 & $83.15 \%$ & $32.44 \%$ & .00 & $42.32 \%$ & .00 \\
\hline Iran & 54 & $72.97 \%$ & $18.08 \%$ & .00 & $22.59 \%$ & .00 \\
\hline Singapore & 65 & $87.84 \%$ & $27.53 \%$ & .00 & $29.36 \%$ & .00 \\
\hline Switzerland & 54 & $87.10 \%$ & $40.52 \%$ & .00 & $44.19 \%$ & .00 \\
\hline South Korea & 53 & $92.98 \%$ & $32.85 \%$ & .00 & $39.07 \%$ & .00 \\
\hline Netherlands & 36 & $66.67 \%$ & $46.19 \%$ & .00 & $58.95 \%$ & .25 \\
\hline Hong Kong & 47 & $88.68 \%$ & $23.62 \%$ & .00 & $26.93 \%$ & .00 \\
\hline Brazil & 41 & $78.85 \%$ & $45.55 \%$ & .00 & $34.04 \%$ & .00 \\
\hline Japan & 43 & $89.58 \%$ & $37.33 \%$ & .00 & $35.94 \%$ & .00 \\
\hline Taiwan & 43 & $93.48 \%$ & $33.80 \%$ & .00 & $41.18 \%$ & .00 \\
\hline Belgium & 34 & $77.27 \%$ & $34.05 \%$ & .00 & $41.75 \%$ & .00 \\
\hline Sweden & 32 & $86.49 \%$ & $43.13 \%$ & .00 & $55.98 \%$ & .00 \\
\hline Saudi Arabia & 28 & $77.78 \%$ & $33.04 \%$ & .00 & $41.01 \%$ & .00 \\
\hline Mexico & 24 & $72.73 \%$ & $35.08 \%$ & .00 & $36.55 \%$ & .00 \\
\hline Turkey & 24 & $72.73 \%$ & $30.49 \%$ & .00 & $24.87 \%$ & .00 \\
\hline Austria & 22 & $78.57 \%$ & $42.72 \%$ & .00 & $55.63 \%$ & .01 \\
\hline
\end{tabular}

\section{References}

Adams, J. (2013). The fourth age of research. Nature, 497, 557-560.

Birnholtz, J. (2007). When do researchers collaborate? Toward a model of collaboration propensity. Journal of the American Society for Information Science and Technology, 58(14), 2226-2239.

Cantwell, B., \& Grimm, A. (2018). The geopolitics of academic science. In B. Cantwell, H. Coates, \& R. King (Eds.), Handbook on the politics of higher education (pp. 130-148). Cheltenham: Edward Elgar Publishing.

Cantwell, B., \& Lee, J. J. (2010). Unseen workers in the academic factory: perceptions of neo-racism among international postdocs in the US and UK. Harvard Educational Review, 80(4), 490-517.

Chahrour, M., Assi, S., Bejjani, M., et al. (2020). A bibliometric analysis of COVID-19 research activity: A call for increased output. Cureus, 12(3), e7357.

Chan, L., Kirsop, B., \& Arunachalam, S. (2005). Open access archiving: the fast track to building research capacity in developing countries. Science Development Network. https://www.scidev. net/global/communication/feature/open-access-archiving-the-fast-track-to-building-r.html

Change (2020). Humanity wins: our fight to unlock 32,544 COVID-19 articles for the world. https://www. change.org/p/brian-napack-unlock-coronavirus-research-for-scientists-89a7ce07-6a46-4ed1-8a73-9745 c2496df5/u/25856587?recruiter=1042086426\&utm_source=share_update\&utm_medium=twitter\&utm_ campaign=share twitter responsive\&recruited by id=5eeac3e0-4b67-11ea-9a2d-1b36a70e02d9.

Chinchilla-Rodríguez, Z., Vargas-Quesadab, B., Hassan-Monterob, Y., González-Molinab, A., \& MoyaAnegóna, F. (2010). New approach to the visualization of international scientific collaboration. Information Visualization, 9, 277-287.

Chiu, W. T., Huang, J. S., \& Ho, Y. S. (2004). Bibliometric analysis of severe acute respiratory syndrome-related research in the beginning stage. Scientometrics, 61(1), 69-77.

Coccia, M., \& Wang, L. (2016). Evolution and convergence of the patterns of international scientific collaboration. Proceedings of the National Academy of Sciences USA, 113, 2057-2061. 
Crowley, M., Wong, E., \& Jakes, L. (2020) Coronavirus Drives the U.S. and China Deeper Into Global Power Struggle. New York Times. https:/www.nytimes.com/2020/03/22/us/politics/coronavirus-us-china.html

Dehghanbanadaki, H., Seif, F., Vahidi, Y., Razi, F., Hashemi, E., Khoshmirsafa, M., \& Aazami, H. (2020). Bibliometric analysis of global scientific research on coronavirus (COVID-19). Medical Journal of The Islamic Republic of Iran (MJIRI), 34(1), 354-362.

Engels, A., \& Ruschenburg, T. (2008). The uneven spread of global science: patterns of international collaboration in global environmental change research. Science and Public Policy, 35(5), 347-360.

Elsevier. (2020). Scopus. Retrieved from https://www.elsevier.com/solutions/scopus

Elsevier. (2017). Scopus Content Coverage Guide. Retrieved from https:/www.elsevier.com/_data/assets/pdf_ file/0007/69451/0597-Scopus-Content-Coverage-Guide-US-LETTER-v4-HI-singles-no-ticks.pdf

Enserink, M. (2003). SARS in China: China's missed chance. Science, 301, 294-296.

Georghiou, L. (1998). Global cooperation in research. Research Policy, 27(6), 611-626.

Hass, R. \& Doug, K. (2020). The US, China, and Asia after the pandemic: more, not less, tension. Brookings. https://www.brookings.edu/blog/order-from-chaos/2020/04/01/the-us-china-and-asia-after-the-pandemicmore-not-less-tension/

Haug, C. (2013). The downside of open-access publishing. New England Journal of Medicine, 368(9), $791-793$.

Hook, D. \& Porter, S. (2020). How COVID-19 is changing research culture. Digital Science. https://digitalscience.figshare.com/articles/How_COVID-19_is_Changing_Research_Culture/12383267

Hossain, M. M. (2020). Current status of global research on novel coronavirus disease (Covid-19): a bibliometric analysis and knowledge mapping. Available at SSRN 3547824.

Huang, F. (2020). China is choosing its own path on academic evaluation. University World News. https://www. universityworldnews.com/post.php?story=20200226122508451

Hutson, M. (2020). Artificial-intelligence tools aim to tame the coronavirus literature. Nature. https://www. nature.com/articles/d41586-020-01733-7

Iglic, H., Doreian, P., Kronegger, L., \& Ferligoj, A. (2017). With whom do researchers collaborate and why? Scientometrics, 112, 153-174.

Jaffe, K., ter Horst, E., Gunn, L. H., Zambrano, J. D., \& Molina, G. (2020). A network analysis of research productivity by country, discipline, and wealth. PLoS One, 15(5), e0232458. https://doi.org/10.1371/journal. pone. 0232458 .

King, D. (2004). The scientific impact of nations. Nature, 430, 311-316.

Kieńć, W. (2017). Authors from the periphery countries choose open access more often. Learned Publishing, 30, $125-131$.

Kituyi, M. (2020). COVID-19: Collaboration is the engine of global science - Especially for developing countries. World Economic Forum. https://www.weforum.org/agenda/2020/05/global-sciencecollaboration-open-source-covid-19/

Kossoff, J. (2020). 2 top French doctors said on live TV that coronavirus vaccines should be tested on poor Africans. Business Insider. https://www.businessinsider.co.za/coronavirus-vaccines-france-doctors-say-testpoor-africans-outrage-2020-4

Larivière, V., Shu, F., \& Sugimoto, S.R. (2020). The coronavirus (COVID-19) outbreak highlights serious deficiencies in scholarly communication. London School of Economics and Political Science: Impact of Social Sciences Blog. https://blogs.lse.ac.uk/impactofsocialsciences/2020/03/05/the-coronavirus-covid-19outbreak-highlights-serious-deficiencies-in-scholarly-communication/

Laudel, G. (2002). What do we measure by co-authorships? Research evaluation, 11(1), 3-15.

Leather, A. J., Butterfield, C., Peachey, K., Silverman, M., \& Sheriff, R. S. (2010). International health links movement expands in the United Kingdom. International Health, 2(3), 165-171.

Lee, Y. C. (2008). Exploring the roles and nature of science: A case study of severe acute respiratory syndrome. International Journal of Science Education, 30, 515-541.

Lee, J. \& Haupt, J.P. (2019). Winners and losers in US-China scientific research collaborations. Higher Education. https://doi.org/10.1007/s10734-019-00464-7.

Leta, J., \& Chaimovich, H. (2002). Recognition and international collaboration: the Brazilian case. Scientometrics, 53, 325-335.

Lundberg, J., Tomson, G., Lundkvist, I., Skar, J., \& Brommels, M. (2006). Collaboration uncovered: exploring the adequacy of measuring university-industry collaboration through co-authorship and funding. Scientometrics, 69, 575-589.

Luukkonen, T., Persson, O., \& Siversten, G. (1992). Understanding patterns of international scientific collaboration. Science, Technology \& Human Values, 17, 101-126.

Marginson, S. (2018). National/global synergy in the development of higher education and science in China since 1978. Frontiers of Education in China, 13, 486-512.

Melin, G. (2000). Pragmatism and self-organization research collaboration on the individual level. Research Policy, 29, 31-40. 
Mercer, P. (2020). Australia-China tensions over call for global COVID-19 probe. Voice of America. https:/www.voanews.com/covid-19-pandemic/australia-china-tensions-over-call-global-covid-19-probe

Mongeon, P., \& Paul-Hus, A. (2016). The journal coverage of web of science and scopus: A comparative analysis. Scientometrics., 106, 213-228. https://doi.org/10.1007/s11192-015-1765-5.

Moore, M. (2020) FBI to warn of Chinese hackers trying to steal coronavirus vaccine data. New York Post. https://nypost.com/2020/05/11/fbi-to-warn-of-hackers-trying-to-steal-coronavirus-vaccine-data/

Myre, G. (2020). U.S. officials: Beware of China and others trying to steal COVID-19 research. National Public Radio. https://www.npr.org/2020/05/11/853696802/u-s-officials-beware-of-china-and-others-trying-to-stealcovid-19-research

National Cyber Security Centre (2020). Advisory: APT groups target healthcare and essential services. https://www.ncsc.gov.uk/files/Joint\%20NCSC\%20and\%20CISA\%20Advisory\%20APT\%20groups\%20 target $\% 20$ healthcare $\% 20$ and $\% 20$ essential $\% 20$ services.pdf

National Science Foundation (NSF) (2018). Science and engineering indicators 2018. NSF. https://www.nsf. gov/statistics/2018/nsb20181/report.

National Science Foundation (2019). Publications Output: U.S. Trends and International Comparisons. National Science Board: Science and Engineering Indicators. https://ncses.nsf.gov/pubs/nsb20206/executive-summary

Nature Index (2019). Connected World: Patterns of International Collaboration Captured by the Nature Index. Retrieved from https://www.natureindex.com/country-outputs/collaboration-graph

Peters, M. A. (2006). The rise of global science and the emerging political economy of international research Collaborations1. European Journal of Education, 41, 225-244.

Pouris, A., \& Ho, Y. S. (2016). A bibliometric analysis of research on Ebola in science citation Index expanded. South African Journal of Science, 112(3-4), 1-6.

Restuccia, A., Lubold, G. \& Hinshaw, D. (2020). Trump Threatens to Permanently Cut Funding to World Health Organization. Wall Street Journal. https://www.wsj.com/articles/chinas-president-pledges-2-billion-forcoronavirus-pandemic-11589802504

Sá, C., \& Sabzalieva, E. (2018). Scientific nationalism in a globalizing world. In B. Cantwell, H. Coates, \& R. King (Eds.), Handbook on the politics of higher education (pp. 130-148). Cheltenham: Edward Elgar Publishing.

Salager-Meyer, F. (2008). Scientific publishing in developing countries: Challenges for the future. Journal of English for Academic Purposes, 7(2), 121-132.

Samimi, A.J. \& Roshan, H.R. (2011). Scientific output and GDP: Evidence from countries around the world. Journal of Education and Vocational Research, 2(2), 38-41.

Scopus (2018). What's new on Scopus: Article Level Open Access Indicator now at the article level and other exciting changes. https://blog.scopus.com/posts/what-s-new-on-scopus-article-level-open-access-indicatornow-at-the-article-level-and-other

Scott, S. (2020). Expert survey series: societal and geopolitical changes in a post-COVID-19 world. Atlantic Council. https://www.atlanticcouncil.org/blogs/geotech-cues/societal-and-geopolitical-changes-in-a-postcovid-19-world/

Smith, M.J., Weinberger, C., Bruna, E.M., \& Allesina, S. (2014). The scientific impact of nations: journal placement and citation performance. Plos One. Retrieved from. https://doi.org/10.1371/journal. pone. 0109195

Stevis-Gridneff M. \& Jakes, L. (2020). World Leaders Join to Pledge \$8 Billion for Vaccine as U.S. Goes It Alone. New York Times. https:/www.nytimes.com/2020/05/04/world/europe/eu-coronavirus-vaccine.html

Subramayan, K. (1982). Bibliometric studies of research collaboration: a review. Journal of Information Science, $6,33-38$.

Sun, X., Kaur, J., Milojevic, S., Flammini, A., \& Menczer, F. (2013). Social dynamics of science. Scientific Reports, 3, 1-6.

Sweileh, W. M. (2017). Global research trends of World Health Organization's top eight emerging pathogens. Globalization and Health, 13(1), 9.

Tabacaru, S. (2019) Web of science versus scopus: journal coverage overlap analysis. University of Texas A\&M libraries: College Station, Texas. Accessed: https:/oaktrust.library.tamu.edu/bitstream/handle/1969.1/175137 /Web\%20of\%20Science\%20versus\%20Scopus\%20Report\%202019.pdf?sequence=4\&isAllowed=y

Tao, T. (2020). New Chinese policy could reshape global STM publishing. Scholarly Kitchen: Society for Scholarly Publishing.. https://scholarlykitchen.sspnet.org/2020/02/27/new-chinese-policy-could-reshapeglobal-stm-publishing/

Tao, Z., Zhou, S., Yao, R., Wen, K., Da, W., Meng, Y., et al. (2020). COVID-19 will stimulate a new coronavirus research breakthrough: A 20-year bibliometric analysis. Annals of Translational Medicine, 8(8).

Togoh, I. (2020). Trump threatens to permanently halt WHO funding and reconsider U.S. membership; China hits Back. Forbes. https://www.forbes.com/sites/isabeltogoh/2020/05/19/trump-threatens-to-permanentlyhalt-who-funding-and-reconsider-us-membership-china-hits-back/\#7e0678b54e75 
Wagner CS. (2018). The collaborative era in science: governing the network Palgrave advances in the economics of innovation and technology series. London: Palgrave Macmillan. Available at https://www.palgrave. com/us/book/9783319949857.

Wagner, C. S., \& Leydesdorff, L. (2005). Mapping the network of global science: comparing international coauthorships from 1990 to 2000. International Journal of Technology and Globalisation, 1(2), 185-208.

Wellcome (2020a). Sharing research data and findings relevant to the novel coronavirus (COVID-19) outbreak [Press Release]. https://wellcome.ac.uk/coronavirus-covid-19/open-data

Wellcome (2020b). Publishers make coronavirus (COVID-19) content freely available and reusable. [Press Release]. https://wellcome.ac.uk/press-release/publishers-make-coronavirus-covid-19-content-freelyavailable-and-reusable

World Bank (2020). GDP (current US\$): All countries and economies. The World Bank. https://data.worldbank. org/indicator/NY.GDP.MKTP.CD

World Health Organization (2020a). WHO Timeline - COVID-19. https://www.who.int/news-room/detail/27-042020-who-timeline\%2D\%2D-covid-19

World Health Organization (2020b). WHO Coronavirus Disease (COVID-19) Dashboard. https://covid19.who.int

Zhang, L., Zhao, W., Sun, B., et al. (2020). How scientific research reacts to international public health emergencies: A global analysis of response patterns. Scientometrics, 124, 747-773.

Publisher's note Springer Nature remains neutral with regard to jurisdictional claims in published maps and institutional affiliations. 